\title{
A No-Holds-Barred Evolution Curriculum for Elementary and Junior High School Students
}

\author{
Joseph Fail Jr.
}

Published online: 20 November 2007

(C) Springer Science + Business Media, LLC 2007

\begin{abstract}
Understanding the basic mechanism of evolution by natural selection together with examples of how it works in nature is crucial for explaining and teaching the workings of biology and ecology to young students. Dobzhansky said it best in his advice to educators of biology: "Nothing in biology makes sense except in the light of evolution." This premise is true at all levels of biology but especially so in the elementary years where foundations of science knowledge are laid. Elementary students are capable of learning cohesive and connected stories of biological principles and learning them within a no-holds-barred arena wherein concepts and processes usually reserved for high school years are taught with special care, appropriate exercises, and patient explanations. This story must include solid introductions to the fundamental principles of evolution by natural selection that are threaded within and alongside those of basic biology and ecology. This paper attempts to make the case for the inclusion of connected stories of biology in the earliest years of education and to include within that education the unifying theme of all biology and ecology studies-evolution.
\end{abstract}

Keywords Elementary evolution education - Evolution education $\cdot$ Elementary science education $\cdot$ Elementary biology education

\footnotetext{
J. Fail Jr. $(\bowtie)$

Department of Natural Sciences, Johnson C. Smith University, Charlotte, NC, USA

e-mail: jfail@jcsu.edu

J. Fail Jr.

Sabbatical Scholar, National Evolutionary Synthesis Center,

Duke University,

Durham, NC, USA
}

\section{Introduction}

Dobzhansky's (1973) famous warning that "nothing in biology makes sense except in the light of evolution," provides convincing and sufficient reason for teaching evolution not only as a part of biology but as its foundation. Because evolution is so basic to all study of biology - and ecology as well - its study should begin with the first introduction of biology to very young students. Convincing the public of Dobzhansky's rule has not been overly successful, as judged by elementary science teaching curricula, elementary science textbooks, or state learning outcomes for elementary students (North Carolina State 2006). The public and their school administrative systems seem to have the view that there is "biological science" and there is "evolution." This perceived separateness thus allows for the teaching of biological fact without consideration of how the facts got there- biology works and so it is. This fragmented view of the presentation of the natural world leads also to a fragmented and largely unconnected content presentation in the teaching of biology. Such soundbite-type presentations of biological topics do not promote a cohesive understanding of the "story" of biology. Teaching the story of biology is crucial to its full understanding, and evolution as the basis of all of biology - must be taught along with connected biology content.

Biology teachers, and students too, of middle and high school know well the problems associated with (a) teaching the facts of biology without theme and (b) attempting to teach biology as a story. The two concepts are opposites of each other. When biology is taught as a story, the facts of biology flow as its theme. The unifying concept of evolution provides the connecting link that ties the facts of biology into its story.

The curriculum discussed here is based on the concept of teaching biology as a connected and thematic story and also 
on experience with teaching young children that strongly supports the premise that they can easily handle both concrete and abstract scientific principles and they can apply these to stories of biological structure and function (Fail 1995, 2003). As with a previous curriculum published with respect to the teaching of ecology (Fail 2003), this evolution curriculum is designed as a year-long and onceper-week series of classes that, like ecology, requires an understanding of basic principles of physics and chemistry and biology taught on a need-to-know basis. The curriculum is designed to be taught both as a course in its own right and also as a series of topics to be taught as judged appropriate by the teacher within the context of elementary studies of biology and ecology.

\section{The Context of Evolution in Elementary Curricula}

The case for the introduction of evolution in the elementary grades is well put forth within the National Science Education Standards released by the National Research Council in 1996 in conjunction with the American Association for the Advancement of Science (1993) and the National Science Teachers Association (1992). The case is summarized in Teaching About Evolution and the Nature of Science (National Academy of Sciences 1998). The standards note in general that, "...all K-12 students should develop understanding and abilities aligned with the following concepts and processes:

- Systems, order, organization

- Evidence, models, and explanations

- Form and function"

With respect to K-4 grade levels, the life science standard notes that: “...elementary school children ought to be able to understand and address questions such as: How do plants get food? How many different animals are there? Where did the dinosaurs go? Why do some animals eat others?..." and further, that one goal is "to begin to understand the complex interaction among all components of the natural environment."

The standard for grades 5-8 notes "...students should develop an understanding of:

- Structure and function in living systems

- Populations and ecosystems

- Reproduction and heredity

- Diversity and adaptations of organisms

- Regulation and behavior"

Such standards demand a quite thorough understanding by teachers of biology, ecology, evolution, and how they interact at basic levels.

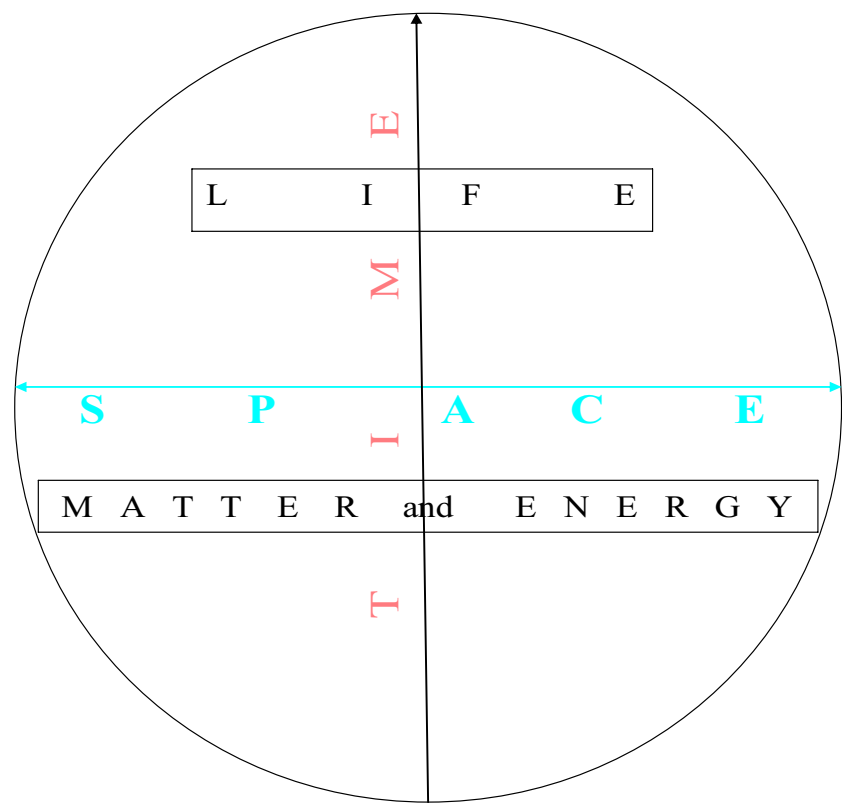

Fig. 1 Evolution functional schematic

Elementary teachers have always had to be adaptable to teaching a wide range of subjects, and the teaching of science can be daunting even for specialists, so asking teachers to teach a cohesive story of biology is asking a lot. Yet, if biology, its associated ecology, and underpinning evolutionary processes are to be effectively learned by future citizens, their teaching must begin early and it must be thorough, "no-holds-barred," and story-based (Fail 2003). Asking "generalist" teachers to bring a story of basic biology and ecology together with evolution into their curriculum can be especially troublesome both at academic and at public school administrative levels. Thus, one of the goals of this curriculum is to have it fit into a general ecology-connected biology curriculum such that principles of evolution may be taught as a separate unit following the acquisition by students of a thorough biological-ecological knowledge base or "sprinkled" throughout the basic biology-ecology curriculum.

A guide to the place of evolution in a biologicalecological curriculum is provided in Figs. 1, 2, 3, and 4. In these depictions, biology, ecology, and evolution are interwoven and connected with each other, abiding by "Dobzahnsky's dictum." Each figure outlines, from differ-

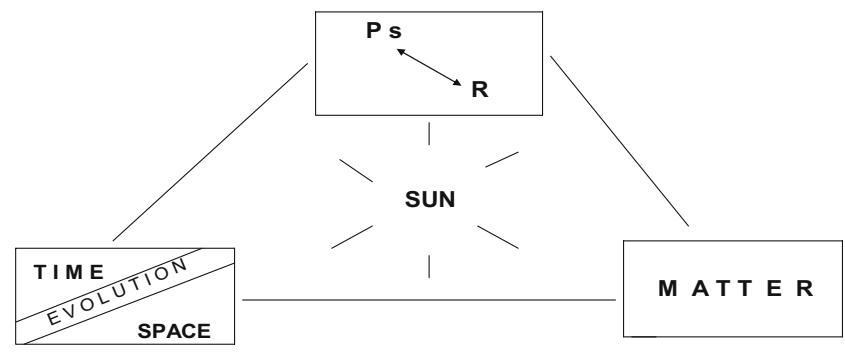

Fig. 2 Ecological functional schematic 
Odum Biological Levels of Organization Spectrum (Abridged)

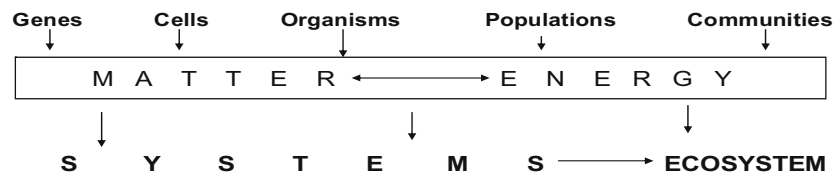

Fig. 3 An overview of biological levels of organization

ent perspectives, the interaction of the three curricular components and how they lead to a cohesive story of how the natural world works.

Figure 1, for example, illustrates the interaction of biology (life) with environment (space) through time (evolution). The others do also, and each are ways for teachers and students who are nervous or intimidated about biology and science to realize connections of the components to each other and to cement in their thinking that all parts are inter-related. All parts are discussed here and in a previous paper (Fail 2003) that this one ties into.

The curriculum units that follow from this philosophical framework are:

I Overview of biological levels of organization

II Chemical structure and function

III Energy

IV Biology: cells and organisms

$\mathrm{V}$ Biology: information storage and transfer

VI Ecology

VII Evolution

\section{The Knowledge Base}

Sections 1 through 6 of this curriculum have been outlined previously (Fail 2003) — and taught to elementary classes several times. The "no-holds-barred" nature of the actual teaching mirrors the titles of the curriculum units. The teaching starts with the basic structural attributes of nature atoms and molecules - then notes how they interact with energy through the first and second laws of thermodynamics. Biological structure and associated function is then studied including the molecular aspects of information storage and transfer. Biological energy processing is studied through analysis of photosynthesis and respiration, which in turn is related to environmental factors - especially temperature and light - and then nutrient cycling is related to the previous energetics study, and all of these processes are tied together with biological structure to create a solid story of ecosystem structure and function (Fail 2003).

It is a mistake to think that evolution can be taught without a basic understanding of biological structure and function (and vice-versa, that biological structure and function can be truly understood without a basic understanding of evolution by natural selection), and so that is where the curriculum must start. To understand how genes and cells work, though, there must also be a basic understanding of how matter and energy work together; thus, chemistry and physics on a "need-toknow" basis are taught as "preparatory topics," which must be understood to then understand the biological structure and function of the world we live in. The basic introductory curriculum syllabus, then, is essentially a mixed biology and ecology set of lessons that set the stage for understanding the mechanisms and principles of evolution by natural selection (Fig. 4). When this last piece of the puzzle of biology is in place, then the student begins to see into the past, understand the present, and logically consider the future. Students can then start telling their own stories of biology.

It bears repeating that the methods of teaching the material leading up to evolution must be story-like, hands-on, active, student-creative, and fun. It should also include a number of quantitative investigations that require students to measure, record, organize, and transform data, and finally to interpret their investigations. A number of methods of doing this are presented by Fail (2003) in his paper on teaching ecology to elementary students.

\section{Introduction to Evolution}

\section{Asking Questions_-“Thinking” Mechanisms}

Students of science, especially very young ones where educational foundations once laid are not easily cast aside, should be steered, as has been noted, strictly away from 'magical' explanations of life. Straightforward, non-magical approaches to teaching the ways of nature build confidence early on in young students that they can 'handle' science. As a way of nature, the mechanism of evolution by natural selection is as elegant a process as there is in biology - as Dobzhansky (1973) notes - and it is therefore simple in its

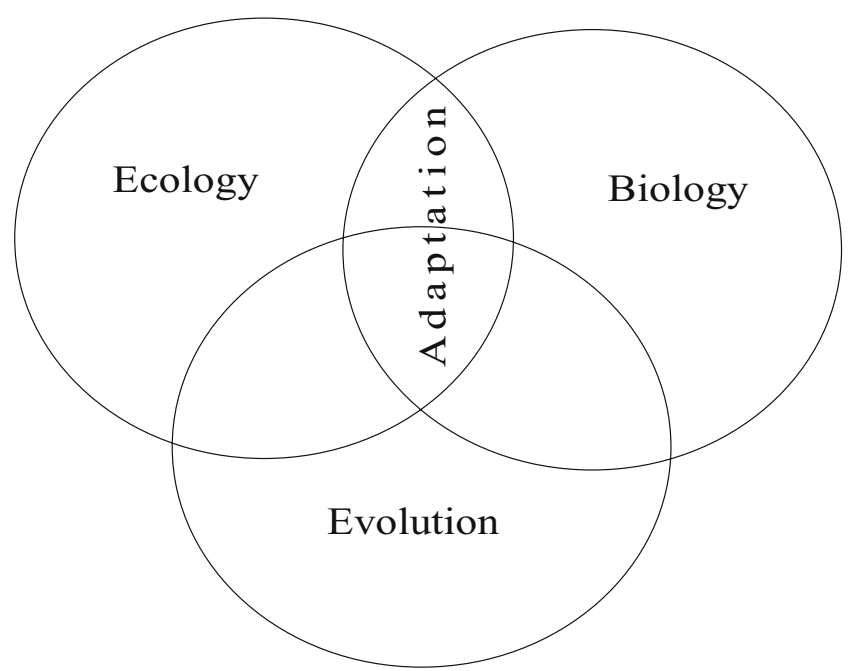

Fig. 4 Interaction of knowledge bases schematic 
essentials. Its elegance and simplicity can only be truly understood, however, in light of the knowledge of the structures and processes that allow its occurrence, hence the necessity of lessons - and their constant and consistent review - in basic chemistry, biology, and ecology.

Evolution by means of natural selection was 'discovered' independently twice. Charles Darwin, of course, published his book on the subject in 1859. Earlier though, A. R. Wallace (1855) published a treatise outlining the same mechanism as Darwin's. Teachers should familiarize themselves with both texts that discuss the discovery, and even have students read selections from both and compare and contrast the ideas in them as well as the way they are expressed. With these readings teachers and students will discover that Darwin and Wallace both, early on, realized the importance of time concerning their own studies of evolution. Thus a good place to begin classroom studies of evolution is its obvious relation to time (Figs. 1 and 2).

Young students can easily relate to the time frame of their lives and their parents and relatives, but geologic time requires thinking in new dimensions and scales. A fun way to approach an appreciation of this new thinking is to construct a time line of biological, geological, and geographical events of the past. This can be done, simply, by employing a 6 foot long narrow strip of paper on the floor marked in even divisions of 50 million years, back to one billion years and by 1 billion year increments back to five billion years. Students then place small cards of major events of biological, geological, and geographical note along the time line. Reference sources for these events may include encyclopedias, but all major biology text books have time lines of varying degrees of refinement. Geography can simultaneously be taught by providing a nearby world map (on the floor so students can crawl about it) so that students can locate places of evolutionary note (Galapagos, Africa, Bering Strait, et al.). Perhaps the chief lesson learned is that not much 'evolution' happens before 500 million years ago but then life 'explodes.' This discovery leads students naturally on to yet more discoveries and questions. Examples include asking questions such as: which came first, food makers (photosynthesizers) or food users (respirators)?; and, did life begin in freshwater or saltwater?; and, what is needed to 'make/evolve' a cell?; and, where did birds come from?; and, of course, where did we come from?

Grasping the immensity of time is troublesome even for adults, and for children time beyond century scale is an unfamiliar concept. One way to illustrate time's span is to use a ball of yarn. Yarn that is neatly dyed with various colors in 1 inch divisions is an interesting and fun way for students to 'experiment' with time ideas while at the same time practicing some simple math. For example, if you make the scale of time so that 1 color $(1 \mathrm{inch})=100$ years, then how far down the hall must you unwind the yarn for
1000 years?, 1,000,000 years?, and on to one billion years... and beyond? So by this means not only are time scales learned but the mathematics to build models of them is too. This is another example of how the study of biology can merge with several disciplines at the same time.

The story of evolution is, of course, ideal for teaching by inquiry (Farber 2003), as well as providing a logical organizing theme of biology (Alles 2001). Nearly the whole study of that story can be taught by asking apparently simple questions that lead to answers beckoning more questions. These questions can readily be constructed using the guide provided by an original source - Darwin himself, in Origin of Species (1859):

If under changing conditions of life organic beings present individual differences in almost every part of their structure...; if there be, owing to their geometrical rate of increase, a severe struggle for life at some age, season, or year...; then considering the infinite complexity of the relations of all organic beings to each other and to their conditions of life, causing an infinite diversity in structure, constitution, and habits, to be advantageous to them, it would be a most extraordinary fact if no variations had ever occurred useful to each being's welfare, in the same manner as so many variations have occurred useful to man. But if variations useful to any organic being ever do occur, assuredly individuals thus characterized will have the best chance of being preserved in the struggle for life; and from the strong principle of inheritance, these will tend to produce offspring similarly characterized. This principle of preservation, or the survival of the fittest, I have called Natural Selection.

Students can have a fun time with this piece. In little committees they can 'decode' the thoughts and restate them - as a connected story in their own words - and then report to the class along with their 'new ideas' and questions about 'what does it all mean?'

Among films, web sites, and books that clearly illuminate Darwin's and Wallace's thinking and discoveries about evolution and that provide insight on 'what does it all mean?' are:

Film: The Voyage of Charles Darwin, $\mathrm{PBS}$ and BBC Time-Life, 1980

Film: Evolution (In 7 parts), PBS, 2001

Web: Understanding Evolution http://evolution.berkeley. edu

Book: The Voyage of the Beagle, C. Darwin, 1840

Book: The Book of Darwin, Simpson, 1982.

Mayr (1977) has provided an easy-to-follow flow chart summarizing Darwin's eloquently described mechanism, and it is this chart that allows us easy access to inquiry. The chart is reproduced in Fig. 5.

All parts of Darwin's description of evolution by natural selection are here, and the simplicity and elegance of how 
Fig. 5 The mechanism of evolution by natural selection: the logic of Darwin and Wallace
Evolution by Natural Selection: Facts and Inferences

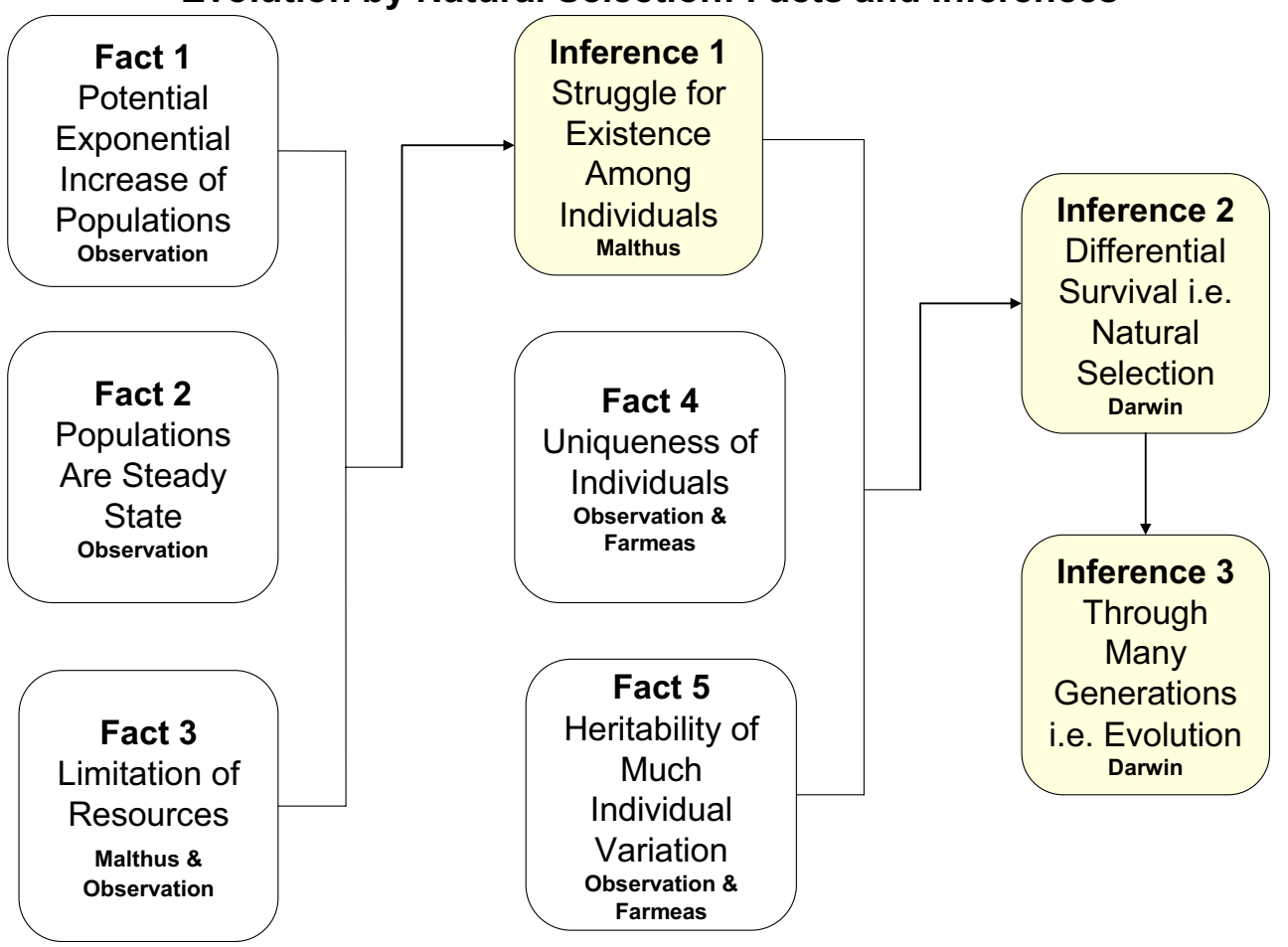

the pieces of the puzzle fit together continue to awe even practiced scientists. For example, the first three facts logically can only lead to the first inference - there has to be biological struggle if its predisposing factors are true. The last facts may be illustrated by consideration of a familiar example - our own uniqueness and yet similarity to relatives - which, when connected to Mayr's "first facts," leads logically and inescapably to differential survival and, thence, natural selection. It is not such a leap to imagine that if this mechanism applies to us then it also must apply to the rest of life.

Perhaps the easiest question set to ask young students that is directly related to these two parallel descriptions of the mechanism of evolution - is "In what ways are we all alike and in what ways are we different?" Dobzhansky (1973) has provided an excellent easy-to-comprehend discussion of this question already, and students may be referred to it as part of class discussions of the question. Asking this question anywhere along the way of the curriculum will generate considerable student discussion. During this discussion, the next question logically becomes "How did we become so similar?" This is where we need scientific (and not magical) answers. If these questions were posed prior to the teaching and discussion of DNA and its function, then the no-holdsbarred scientific answer becomes the discussion of the genetic code and how it works (Fail 2003).

Understanding the structure and function of DNA is crucial to teaching evolution as a "materialistic" phenomenon (Futuyma 2006) dependent wholly on the minutest of materials - molecules and the atoms that make them up and also dependent on the physical laws that govern their interaction - the first and second laws of thermodynamics. Students soon come to a logical and "magic-free" way of describing the way life works.

\section{Selection and Adaptation; Commonality yet Diversity}

A second series of discussions and questions may center on the concept of "adaptation" and the "natural selection" producing them, or to phrase the discussion differently, "how did we become so different?" This concept may easily be discussed in light of our previous questions - and answers - on similarities. Adaptations are characters that make us different, say, from a fish. Students can readily understand how common fish are "adapted" to their watery environment- they are streamlined and all have similar body plans that allow for skillful movement in their naturally selective environment. So fish fit their ecological niche and thus they have successfully answered a question posed by nature - they have been selected "for" (rather than "against") - and thereby have become "adapted." This naturally leads to the question of "how has this adaptation occurred," which leads to more materialistic and energetics-based ideas on how evolution works.

Similarly, we may observe birds in the air and draw conclusions that, although there are similarities in skeletal plans of birds and fishes due to the similar selection pressures of fluid environments, air life, with its own set of selection pressures, requires different answers - adaptations - to "nature 
questions" from those that sea life does. Students can be asked to look at just skeletons of birds and fishes and discuss how we might use a similar body plan in both, but through evolutionary (non-magic) change, adapt a body plan - a "morphology" - to a thoroughly different environment. Children may like drawing sketches of adaptations (fins, wings, arms, etc.), as well as using preserved specimens illustrating adaptations and then placing them at the position of their first appearance along their geologic time line. Visits to zoos, arboreta, and natural history museums are excellent field laboratories within which to study real-life adaptation examples.

The concept of common origin and descent with modification through selection of traits and adaptation to the environment is, at the same time, an intriguingly complex and yet elegantly simple teaching challenge. Students will have already been taught about "hard" inheritance, the concept that hereditable factors are passed along ultimately through atoms and (DNA) molecules. They will already know that all cells come from pre-existing cells, and they will understand the concept of variation in phenotype arising from recombinations of genotypic DNA. Thus, they will understand the basic mechanisms behind individual similarities and their variation and populational descent with change from common ancestors.

The simplest classroom exercise/game to teach concepts of common origin is to create time lines with branches (using biology textbooks, encyclopedias, and the internet as references) on the classroom floor and locate groups of organisms along the line and its branches. The ultimate logical conclusion is that organisms share common ancestors, which, if taken to its ultimate beginning, starts with one prokaryotic ("why?") cell.

A cute game to play to illustrate these ideas is to have pairs of students stand together before the class with pictures of their parents and have the class list similarities and differences between the students and between the students and their parents - and then explain the differences, especially in terms of hard inheritance - both from Mendelian and molecular genetics points of view. If other organisms - pet cats, dogs, frogs, mice, bees, earthworms, plants of many kinds - or their models (pictures) or skeletons are added to this game, then students quickly come to intuitive understandings of the possible results of descent with modification. Throughout this game, connections between organismal structure and function and the environment should be stressed as examples of "adaptation," that is, biological answers to questions and problems posed by nature.

A fine add-on to this game is to prepare evolutionary trees of these organisms, which would be most effectively taught if students worked in groups in class and came up with reasoned relationships on their own and then "published" them to present to the class and to their parents. Teachers might well consider doing this work in several lengthy time periods so that students have time to talk and consider among themselves and then to draw group conclusions that are then written up in a good solid scientific report supported with references, thus teaching writing alongside science.

Selection by nature - on adaptations - is, of course, tied to the concept of "survival of the fittest." There are many ways to approach discussion and illustration of this concept at elementary levels. In all cases of examples of adaptations and selection on them, it is important to re-stress and remind students that all adaptations are DNA- and, therefore, "materially"-based. Adaptations and the natural selection on them are not magic. Obvious stories of selection and survival of the fittest that are found in common biology textbooks include lions eating slow wildebeests (predator-prey), (maybe not so obvious) selection for "hurricane genes" in coastal plain trees (environmental pressure), and selection pressures on camouflaged English peppered moths (environmental pressure and predator-prey).

In humans, the interesting story of sickle-cell - abnormal crescent-shaped red blood cells - well illustrates the molecular basis of adaptation's origin as random mutation. In this case, a single DNA base-pair change leads to amino acid change, which leads to protein change and phenotypic red blood cell change, and thence, adaptation in response to an environmental challenge (malaria in Africa), and finally selection on the adaptation. Thus, this single example reviews DNA structure, transcription, and translation; concepts of genotype vs phenotype; and environmental and biological selection on adaptation. It is the ideal simple story of the basis of evolution and is all the more impactful on students because the subjects of the story are people of black African origin. The story has many interesting and quite understandable twists and turns that students can explore.

For instance, the mutation would appear not to be useful towards survival of its possessors (oxygen deprivation and clogged capillaries) and it is not - in malaria-free areas but it is the difference between life (and reproductive success) and death in areas of malarial infestation. Asking questions concerning this evolutionary, ecological, and human social story can lead students to quite interesting interdisciplinary studies, including the relation of sickle cell and malaria to agriculture and tropical forest deforestation (Volpe 1985). Class polls of students with the trait followed by construction of family trees show students' paths of inheritance, which illustrate several principles of inheritance already discussed in class.

Is there, then, a connection between adaptation of organisms to their environment, selection on those adaptations, and diversity? This question has been famously rephrased as "Why are there so many animals?" by 
Hutchinson in his classical 1958 essay. His answer was that the more species an ecosystem or environment has, the more stable is the community that arises within it. This is because, "Just as adaptive evolution by natural selection is less easy in a small population of a species...because the total pool of genetic variability is less, so it is probable that a group containing many diversified species will be able to seize new evolutionary opportunities more easily than an undiversified group" (Hutchinson 1959). Eldridge (1998), in addressing the same idea, notes that, "Complex ecosystems - with many different species eating many others, and with competition for finite resources between species with similar needs - mean that the least little change in one population has implications, even evolutionary consequences, for many others of the same system."

Therefore, species diversity of ecosystems - much threatened by human activity in this modern age - is yet apparently crucial for the maintenance of these systems and for the maintenance of constituent human species as well. Young students need to learn these lessons, and if they do, then there is perhaps some hope of maintaining a healthy earth for future generations.

One interesting and simple class experiment that will test hypotheses concerning diversity and ecosystem function is to use three containers of the same size - half milk cartons with bottom holes will work - and place soil and seeds of one species in one then two in the next and then three in the next. Ask students to faithfully water all containers with the same amount of water each time, and after 3 weeks, measure the total oven-dry biomass of each container. Which system would have the most mass? Why? What is the relationship of these results to evolution by natural selection? This experiment is a variation of a study by Harper and Clatworthy (1963, and summarized by Odum 1983) of competing clovers.

Animals may also be used to test hypotheses concerning diversity and niche space. Flour beetles are easy to use. Bread companies or student homes may be able to provide populations of two separate species of flour beetles that are also allowed to mingle separately and together in chambers of flour. The number of individuals present after some time period (1 week) is then determined (Park 1954). Can two species using the same niche (what is a niche?) survive when placed together in the same ecosystem? A similar experiment can be performed in a water system using Paramecium species (Allee et al. 1949).

\section{Speciation-Appearance of New Species}

How do new species arise? This is a question of great intrigue, and mystery too. Charles Darwin himself noted that his book was an attempt "...to throw some light on the origin of species - that mystery of mysteries" (Darwin 1859). His only diagram ("Chapter IV: Natural Selection; Or The Survival Of The Fittest") in Origin of Species - his drawing of an evolutionary "tree" illustrating species origins and descent with modification - provided his ideas of answers to the question. This diagram is an excellent avenue - after only the briefest of introduction - for children to discuss and ask questions about its meaning. It can even be a means to introduce the whole concept of evolution so elegantly (and deceptively) simple is it crafted. It can, and should be, reconsulted on many occasions during the course of the evolution curriculum. A simplified version of a Darwinian tree is shown in Fig. 6.

Evolution by natural selection provides two obvious mechanisms that could lead to new species (Fig. 6). The first, cladogenesis, is the division of a lineage - or line of descent - into two or more lines. This most obviously might happen if two populations of a single species wandered off - or were separated - into two opposite environments (hot and wet vs cold and dry) separated by geographic barriers (mountains), and then over the course of 1,000+ generations, sets of variations (DNA-based traits) were selected for or against such that the separate populations became so (DNA) different that if the derived (decended from the "root") populations remet in the future they could not produce viable offspring.

Fig. 6 Speciation

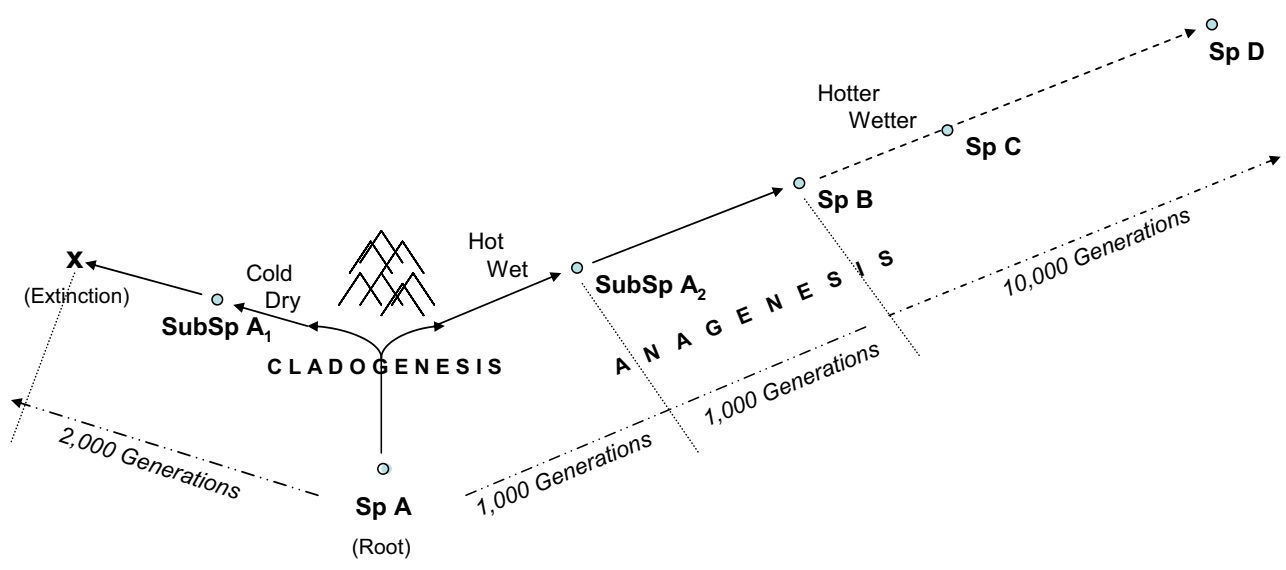


The second mechanism - anagenesis - is the transformation of a lineage over time. Thus, if each of the two environments described gradually change over time (leading to the formation of "subspecies"), then it may come to pass that, after 2,000 generations, the original two populations had so changed (their DNA) that the 2,000th generation of individuals would not have been able to successfully exchange genes with the originally derived 1,000th. These derived new species would thus be the current version of original older species that had changed over time. So in our (story) scenario, selection on individuals' DNA of earlier populations in response to slow environmental change had led to a current population of genes that would not be reproductively compatible with the earlier gene population. Extinction happens when environmental change is so drastic that the species' DNA "cannot keep up with" the change and so the species dies out. Both concepts are clearly described in Volpe (1985) and Futuyma (2006), and two web sites offer exploration and explanations by scientists of the "tree of life" (http://www.tolweb. org/tree) and of "macroevolution" (http://eog.nescent.org/ NABTsymposium.htm) _evolution above the species level. Classroom study of the proposed pathways of evolution of Homo sapiens - humans - over time is an excellent means to become familiar with both types of mechanisms of speciation, and it is a topic that students will spend near endless hours discussing.

An interesting game in class is to "act out" Fig. 6. Groups of students can either construct or draw "variations on species themes," suggest environmental changes, and then "evolve" new phenotypes - physical forms (with changed DNA) - to match the changed environments. There is also a web site (http://wps.prenhall.com/esm_freeman_evol_3) in which students can "construct" a set of lizards and other organisms and then figure out a tree of relationships.

\section{Human Evolution}

The topic of human evolution should not be avoided. Children, of course, have the most vigorous imaginations and curiosity of all evolved creatures, so they thirst to talk about ideas of "How did we get here?" Besides the textbooks by Futuyma (2006) and Volpe (1985) and many others, excellent film series exist that explore theories of human evolution. These include Journey of Man (PBS Video 2003) and Evolution (PBS Video 2001) - both available from the PBS (http://www.pbs.org). National Geographic has human evolution stories in many volumes of their magazine, the most comprehensive and extensive of which is The Search for Our Ancestors (National Geographic Society 1985).
The key to exploring the topic of human evolution is to use authority (texts and films, as above) and to remind students of the materialist nature of evolution by natural selection - that our job as scientists is to stay strictly away from magic and, therefore, to discuss this topic in light of the science behind evolution. Debate can fruitfully be centered about discussion of the several proposed pathways by which we got here. Darwin also explored the evolution of humans (Darwin 1871), and his famous work on the topic can be used in many ways, including assigning parts for reading, summarizing, and critiquing by students and as student group investigative and reporting assignments.

\section{Conclusion}

The story of biology is too exciting. What other explanation is there for treating the discipline so patchily, so un-storylike in the elementary grades, and indeed throughout high school as well? Of all the disciplines that a student is subjected to over the course of their years of formal education, none is more amenable to exciting story-telling than biology. The scientifically unquestioned unifying thematic story in all of biology is that of evolution by natural selection. The story of its mechanisms, the stories of its pathways and its results - including the students themselves - and its adaptability for hypothesizing the fate of the planet make understanding evolution a key to citizen involvement in science. That story is so endlessly filled with adventure that very young students may sit for hours, if properly guided in the flow of biological story-telling, pondering questions and puzzles posed by its study. As a group learning vehicle, the study of biology together with its interaction with the environment leading to evolutionary change has no equal as a means to foster and focus directed creative student effort and study.

The telling of that story is also the near perfect venue for writing practice - the only true way to learn how to write competently. When students have a clear understanding of the story of biology and its basic driving forces and mechanisms, they may use their knowledge to write true stories that illuminate the workings of the world around them.

Finally, if we as a people hope to provide solutions to the global ecological threats to our planet, then we must have a citizenry that understands clearly the effects of our individual and collective actions on future generations. Understanding the story of biology and its relationship to the environment and the endless life process of adaptation to environmental change - evolution - is crucial to this effort. 


\section{References}

Allee WC, Emerson AE, Park O, Park T, Schmidt KP. Principles of animal ecology. Philadelphia: W. B. Saunders; 1949.

Alles DL. Using evolution as the framework for teaching biology. Am Biol Teach 2001;63:20-3.

Darwin C. The voyage of the beagle. Recent publication. New York: Doubleday; 1840.

Darwin C. The origin of species. Chapter 4: Summary. Recent publication. New York: Random House; 1859.

Darwin C. The descent of man and selection in relation to sex. Recent publication. New York: Random House; 1871.

Dobzhansky T. Nothing in biology makes sense except in the light of evolution. Am Biol Teach 1973;35:125-9.

Eldridge N. Life in the balance: humanity and the biodiversity crises. Princeton: Princeton University Press; 1998.

Fail JL Jr. Teaching ecology in urban environments. Am Biol Teach 1995;57:522-5.

Fail JL Jr. A no-holds-barred ecology curriculum for elementary and junior high school students. Am Biol Teach 2003;65:341-6.

Farber P. Teaching evolution and the nature of science. Am Biol Teach 2003;65:347-54.

Futuyma DJ. Evolution. Sunderland: Sinauer; 2006.

Harper JL, Clatworthy JN. The comparative biology of closely related species. VI. Analysis of the growth of Trifolium repens and $T$. fragiferum in pure and mixed populations. J Exp Bot $1963 ; 14: 172-90$
Hutchinson GE. Homage to Santa Rosalia or why are there so many animals? Am Nat 1959;93:145-59.

Mayr E. Darwin and natural selection. Am Sci 1977;65:321-7.

National Academy of Sciences. Teaching about evolution and the nature of science. National Academy Press, Washington DC, USA; 1998. Includes: Ch. 4: National Science Education Standards composed of recommendations of: The National Research Council, 1996; AAAS Benchmarks for Science Literacy, 1993; NSTA The Content Core, 1992.

National Geographic Society. The search for our ancestors. In: Kenneth W, editor. Natl Geogr Mag 1985;168:561-629.

North Carolina State learning outcomes. NC State Board of Education; 2006.

Odum EP. Basic ecology. Philadelphia: Saunders; 1983.

Park T. Experimental studies of interspecific competition. II. Temperature, humidity, and competition in two species of Tribolium. Physiol Zool 1954;27:177-238.

Simpson GG. The book of Darwin. New York: Washington Square Press; 1982.

Volpe EP. Understanding evolution, 5th ed. Dubuque: William C. Brown; 1985.

Wallace AR. On the law which has regulated the introduction of new species. Ann Mag Nat Hist 1855;26:184-96 (http://www.wku. edu/ smithch/wallace/writings.htm).

PBS Video. Voyage of Charles Darwin. London: BBC/Time-Life; 1980.

PBS Video. Evolution; 2001. http://www.pbs.org.

PBS Video. Journey of man; 2003. http://www.pbs.org. 